\title{
Effect of adenylyl cyclase activation on intracellular and extracellular cAMP and cGMP in preimplantation cattle blastocysts
}

\author{
M. Grealy* and J. M. Sreenan
}

Animal Reproduction Department, Teagasc, Agriculture and Food Development Authority, Athenry, Co. Galway, Ireland

\begin{abstract}
The effects of direct and indirect activation of adenylyl cyclase on the production of intracellular and extracellular cAMP and cGMP by 13- to 16-day-old cattle embryos were determined. Embryos were incubated for $2 \mathrm{~h}$ in a Krebs Ringer bicarbonate medium containing the phosphodiesterase inhibitor isobutyl-methylxanthine, to which stimulating agents forskolin $\left(100 \mu \mathrm{mol} \mathrm{l}^{-1}\right)$, cholera toxin $\left(2 \mu \mathrm{g} \mathrm{ml}^{-1}\right)$, or both were added. Total (intraand extracellular) basal cAMP and cGMP concentrations ranged from $6.65 \pm 0.895$ to $3.4 \pm 0.708 \mathrm{fmol}^{\mathrm{g}} \mathrm{g}^{-1}$ protein in 13-day-old embryos and from $4.05 \pm 1.151$ to $0.19 \pm 0.041$ fmol $\mu \mathrm{g}^{-1}$ protein in 16-day-old embryos. Forskolin induced an increase $(P<0.001)$ in cAMP that ranged from 5.4-fold on day 13 to 2.7 -fold on day 16 , whereas cholera toxin induced an increase $(P<0.001)$ that ranged from 30 -fold at day 13 to 21 -fold at day 16 , similar to the effect of forskolin and cholera toxin combined. Individually, forskolin and cholera toxin had no effect on cGMP concentrations, but together they induced an increase $(P<0.05)$. cAMP $(P<0.01)$ and CGMP $(P<0.001)$ concentrations decreased with embryo age from day 13 to day 16 for all treatments; the decrease was greater for CGMP than cAMP (5-24-fold versus 1.6-3.3-fold, respectively). It is concluded that inducible adenylyl cyclase is present in 13- to 16-day-old cattle embryos and that the embryos secrete CAMP and CGMP into the incubation medium. In addition, basal and inducible concentrations of CAMP and CGMP decrease with embryo age from day 13 to day 16. These observations indicate that cAMP and cGMP may have a role in the rapid embryonic cell proliferation that occurs at this time or in signalling to the endometrium.
\end{abstract}

\section{Introduction}

cAMP and cGMP are present in, and secreted by, 14- to 16day-old cattle blastocysts during in vitro culture (Grealy et al., 1997). In adult cells, cAMP and cGMP are involved in cell cycle control, differentiation and cell proliferation (Boynton and Whitfield, 1983; Dumont et al., 1989; Christensen et al., 1996; Garcia-Ocana et al., 1996; Sarkar et al., 1997), and they may have similar roles in cell proliferation and differentiation during preimplantation embryo development.

Many hormones, neurotransmitters and other 'first messengers' act by controlling cAMP concentrations. This control is achieved by altering the activity of adenylyl cyclase, the enzyme that synthesizes cAMP. Binding of the first messenger to an appropriate receptor causes activation of the $G$ protein Gs, which in turn stimulates adenylyl cyclase (Sunahara et al., 1996), thereby increasing cellular cAMP concentrations. Adenylyl cyclase may be activated directly by forskolin, which reversibly binds to the catalytic subunit (Seamon and Daly, 1981), whereas the G protein may be activated directly by cholera toxin, which catalyses the

*Present address: Biochemistry Department, National University of Ireland, Galway, Ireland.

tCorrespondence.

Received 1 September 1998.
ADP ribosylation of the $\alpha$ subunit of the Gs regulatory protein (Fishman, 1990). cAMP exerts its effects in the cell by binding to, and activating, its specific protein kinase, cAMPdependent protein kinase (PKA), which in turn, activates or inhibits other proteins in the cell by phosphorylation.

cGMP is formed after activation of guanylyl cyclases and activates or inhibits several target proteins in the cell. The effects include activation of CGMP-dependent protein kinase $(\mathrm{PKG})$, regulation of ion channels, and activation or inhibition of cAMP phosphodiesterases (PDE) which break down cAMP in the cell (Goy, 1991). In this way, cGMP interacts with the CAMP pathway.

Both cAMP and cGMP are exported from mammalian cells (for reviews see Barber and Butcher, 1983; Hamet and Tremblay, 1991). Although the physiological functions of extracellular cAMP or CGMP are not fully resolved, the egress of these cyclic nucleotides may be a means, in addition to PDE, of terminating their action as intracellular signal transduction agents. However, extracellular cAMP and cGMP may also participate in signalling, either by binding to cell surface receptors or by being degraded to adenosine or guanosine, which then act as agonists at purinergic receptors. In kidney cells, extracellular cAMP stimulates, and cGMP inhibits, sodium chloride absorption in the medullary thick ascending limb (Amlal et al., 1996). Cattle blastocysts 
secrete cAMP and CGMP during culture in vitro (Grealy et al., 1997), but the function of these secreted cyclic nucleotides in cattle embryos has not been established.

The adenylyl cyclase present in bovine and mouse oocytes may be atypical because it is insensitive to cholera toxin but responds to forskolin stimulation (Manejwala et al., 1986; Bilodeau et al., 1993). This is in contrast to the adenylyl cyclases of adult cells, which respond both to cholera toxin and forskolin (Sunahara et al., 1996). In mouse embryos, sensitivity to cholera toxin increases from the eight-cell to the blastocyst stage (Manejwala et al., 1986). There is no information on the nature or activation of adenylyl cyclase in cattle embryos, although changes in sensitivity to stimulation may be important in the control of development.

The aims of this study were as follows: (i) to establish dose-response effects of the PDE inhibitor isobutylmethylxanthine (IBMX), the direct adenylyl cyclase activator forskolin, and the indirect adenylyl cyclase activator cholera toxin on CAMP and CGMP concentrations in 14- or 15-dayold cattle embryo; (ii) on the basis of the results from the dose-response investigation, to investigate the effects of activation of adenylyl cyclase, either directly or indirectly, on intra- and extracellular cAMP and cGMP concentrations in 13- to 16-day-old cattle embryos; and (iii) to examine whether sensitivity to adenylyl cyclase activators changes from day 13 to day 16, which is the crucial period for embryo-maternal signalling and embryo survival.

\section{Materials and Methods}

\section{Embryo recovery}

Preimplantation embryos $(n=135)$ were recovered from 18-month-old Hereford-cross heifers $(n=32)$ as described by Grealy et al. (1997). Briefly, heifers were superovulated with 1500 iu PMSG (Folligon; Intervet, Cambridge) and luteolysis was induced with $500 \mu \mathrm{g}$ cloprostenol (Estrumate; Coopers Animal Health, Berkhamsted) $48 \mathrm{~h}$ later. Artificial insemination was carried out at $6 \mathrm{~h}$ and $18 \mathrm{~h}$ after the onset of standing oestrus. Embryo recovery was carried out during mid-ventral laparotomy performed under licence in accordance with the European Community Directive, 86-609EC. Thiopentone sodium ( 5 g, i.v.; Rhone Merieux, Harlow) was used as the initial anaesthetic followed by closed circuit anaesthesia with halothane (May and Baker, Dagenham) and oxygen. Hatched elongated blastocysts were flushed from the uterus on days 13,14, 15 and 16 (day $0=$ day of first observation of standing oestrus). The composition of the collection medium was $0.1 \%(\mathrm{w} / \mathrm{v})$ polyvinyl-alcohol, 139 $\mathrm{mmol} \mathrm{NaCl} \mathrm{l}^{-1}, 2.7 \mathrm{mmol} \mathrm{KCl} \mathrm{l}{ }^{-1}, 0.89 \mathrm{mmol} \mathrm{CaCl} \cdot 2 \mathrm{H}_{2} \mathrm{Ol}^{-1}$, $1.47 \mathrm{mmol} \mathrm{KH_{2 }} \mathrm{PO}_{4} \mathrm{l}^{-1}, 0.49 \mathrm{mmol} \mathrm{MgCl} \cdot 6 \mathrm{H}_{2} \mathrm{O} \mathrm{l}^{-1}, 7.46 \mathrm{mmol}$ $\mathrm{Na}_{2} \mathrm{HPO}_{4} \cdot 2 \mathrm{H}_{2} \mathrm{O} \mathrm{l}^{-1}, 1 \mathrm{mmol}$ glucose $\mathrm{l}^{-1}$ and $0.5 \mathrm{mmol}$ pyruvic acid (sodium salt) $\mathrm{l}^{-1}, \mathrm{pH}$ 7.3. Embryo recovery was carried out between 09:00 $\mathrm{h}$ and 14:00 $\mathrm{h}$ on each day. After recovery, embryos were washed three times in sterile collection medium at $35^{\circ} \mathrm{C}$ and graded for apparent viability on a scale of 1 (excellent) to 3 (degenerate) on the basis of morphology and expected developmental stage for age according to Betteridge et al. (1980) and Grealy et al. (1996). Only grade 1 and 2 embryos were included in the study. Embryos occasionally fragmented during the recovery procedure, but when fragments corresponded to the above criteria with regard to width and granulation they were included in the study.

\section{Embryo incubation and storage}

Embryos or embryo fragments were incubated individually in $1 \mathrm{ml}$ of a Krebs Ringer bicarbonate medium (KRB) in fourwell plates (Nunc, Roskilde) in a humidified atmosphere of $5 \% \mathrm{CO}_{2}$ in air at $38.5^{\circ} \mathrm{C}$ for $2 \mathrm{~h}$. The composition of the incubation medium was $108 \mathrm{mmol} \mathrm{NaCl}^{-1}, 4.78 \mathrm{mmol} \mathrm{KCl}^{-1}$, $1.71 \mathrm{mmol} \mathrm{CaCl} 2 \cdot 2 \mathrm{H}_{2} \mathrm{O} \mathrm{l}^{-1}, 1.19 \mathrm{mmol} \mathrm{KH_{2 }} \mathrm{PO}_{4} \mathrm{l}^{-1}, 1.19 \mathrm{mmol}$ $\mathrm{MgSO}_{4} \cdot 7 \mathrm{H}_{2} \mathrm{O} \mathrm{l}^{-1}, 25 \mathrm{mmol} \mathrm{NaHCO} \mathrm{l}^{-1}, 1 \mathrm{mmol}$ glucose $\mathrm{l}^{-1}$, $0.5 \mathrm{mmol}$ pyruvic acid (sodium salt) $1^{-1}$ and $0.1 \%(\mathrm{w} / \mathrm{v})$ polyvinyl-alcohol, $\mathrm{pH} 7.4$ when gassed with $\mathrm{CO}_{2}$.

For determination of dose-response relationships, the PDE inhibitor IBMX (0.1-10 $\left.\mathrm{mmol}^{-1}\right)$, the direct activator of adenylyl cyclase forskolin (1-100 $\left.\mathrm{mol} \mathrm{l}^{-1}\right)$ and the indirect activator of adenylyl cyclase cholera toxin $\left(0.2-20 \mu \mathrm{g} \mathrm{ml} \mathrm{l}^{-1}\right)$ were used. Doses of IBMX, forskolin and cholera toxin were within the range used in studies on cattle oocytes (Bilodeau et al., 1993) and mouse embryos (Manejwala et al., 1986). On the basis of the results from the dose-response study, 13- to 16-day-old cattle embryos were treated with $100 \mu \mathrm{mol}$ forskolin $\mathrm{l}^{-1}, 2 \mu \mathrm{g}$ cholera toxin $\mathrm{ml}^{-1}$, or a combination of $100 \mu \mathrm{mol}$ forskolin $\mathrm{l}^{-1}$ and $2 \mu \mathrm{g}$ cholera toxin $\mathrm{ml}^{-1}$. IBMX was

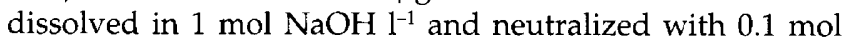
$\mathrm{HCl}^{-1}$ to give a $50 \mathrm{mmol} \mathrm{l}^{-1}$ stock. This was dissolved in KRB to give the final concentration. Forskolin was dissolved in dimethyl sulfoxide (DMSO) to give a $50 \mathrm{mmol} \mathrm{l}^{-1}$ stock and cholera toxin was dissolved in distilled $\mathrm{H}_{2} \mathrm{O}$ to give a $1 \mathrm{mg} \mathrm{ml}^{-1}$ stock. These stock solutions were diluted in KRB and IBMX to give the final concentrations. The preparations of IBMX, forskolin, cholera toxin and DMSO were obtained from Sigma (Poole).

After incubation, embryos were washed three times in collection medium and once in glucose-free collection medium to avoid interference with the protein assay, and were transferred to $200 \mu \mathrm{l}$ ice-cold $95 \%$ ethanol (Merck, Darmstadt) in $1.5 \mathrm{ml}$ conical plastic tubes (Safe-twist, Eppendorf, Hamburg) and stored in liquid nitrogen. Samples of the final wash, of similar volume to the medium in which the embryos were transferred, were also stored frozen in $200 \mu \mathrm{l} 95 \%$ ethanol for use as assay blanks.

At the end of each $2 \mathrm{~h}$ incubation, a $200 \mu \mathrm{l}$ sample of incubation medium was taken for estimation of cyclic nucleotides. This was also transferred to $200 \mu 195 \%$ ethanol and stored as described for the embryo samples.

\section{Assays for cAMP, cGMP and protein}

Each embryo sample $(n=135)$ was assayed for cAMP, cGMP and protein. The assays were carried out according to Grealy et al. (1997). Briefly, embryos were thawed, sonicated and centrifuged. The supernatants were dried down and assayed for cAMP and cGMP by acetylated radioimmunoassay ${ }^{125} \mathrm{I}$, 

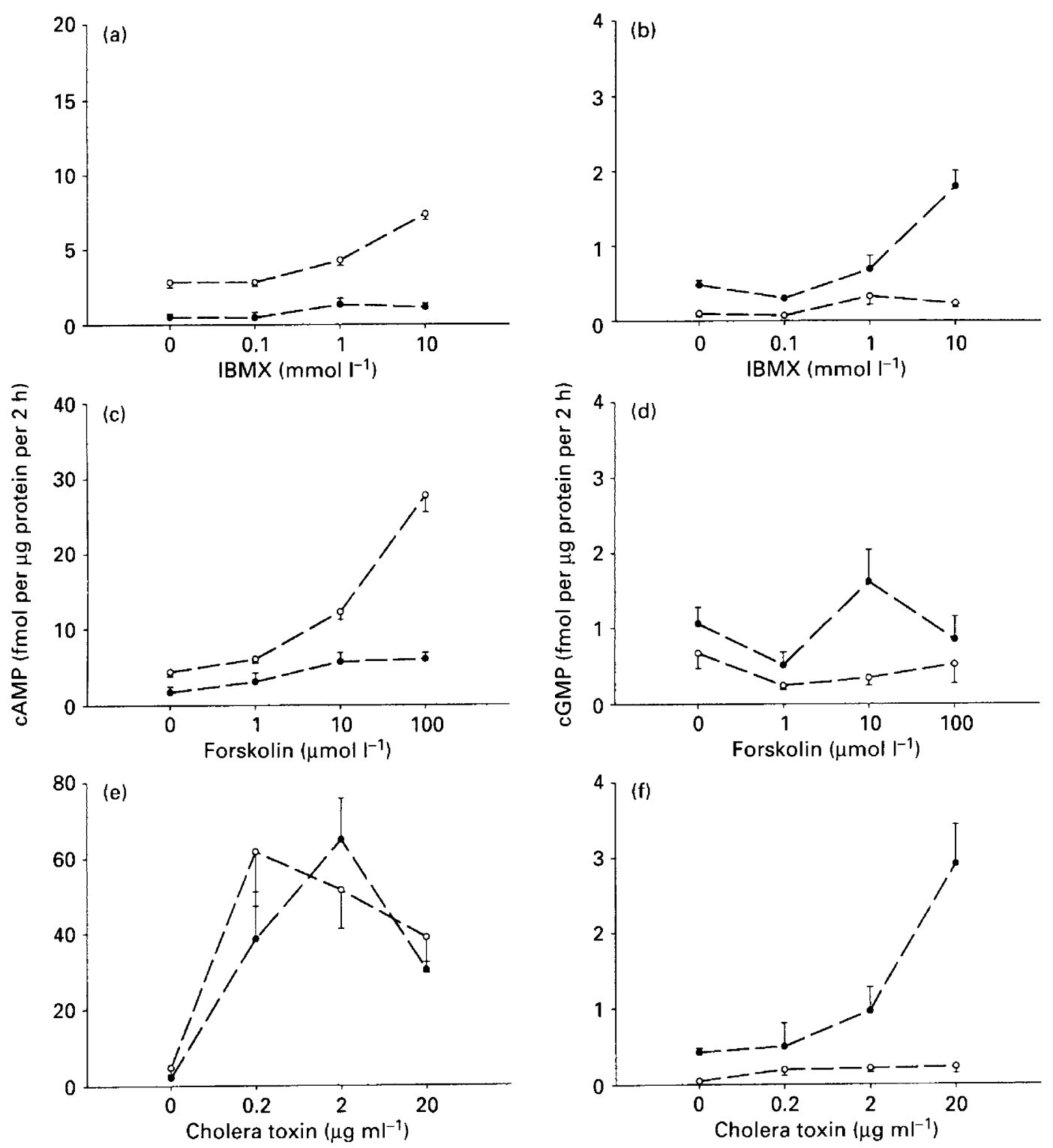

Fig. 1. Dose-dependent effects of isobutyl-methylxanthine $(\operatorname{IBMX})(a, b)$, forskolin $(c, d)$ and cholera toxin $(e, f)$ on intracellular $(\mathrm{O})$ and extracellular $(\bullet)$ cAMP $(\mathrm{a}, \mathrm{c}, \mathrm{e})$ and cGMP $(\mathrm{b}, \mathrm{d}, \mathrm{f})$ in 14- or 15-day-old cattle embryos. Data represent least-square means \pm SEM of at least four replicates.

New England Nuclear, Du Pont, Stevenage). The protein content of the pellets was measured by the Pierce Micro BCA protein assay (Pierce and Warriner Ltd, Chester). Results are expressed as fmol $\mu \mathrm{g}^{-1}$ protein \pm SEM. The intra- and interassay coefficients of variation (CV) were 7.5 and $8.9 \%$ for cAMP, 5.3 and $9.5 \%$ for CGMP, and 3.7 and $6.1 \%$ for protein, respectively.

cAMP and CGMP concentrations in the embryos (intracellular) and in the incubation medium (extracellular) were measured as per microgram embryonic protein to eliminate variation due to the difference in the size of embryos recovered on a given day. Concentrations of cAMP and cGMP in the incubation medium were corrected for volume and then divided by embryo protein content. Total cAMP and cGMP were estimated as intracellular cAMP + extracellular cAMP and intracellular cGMP + extracellular cGMP.

\section{Statistical analyses}

The cAMP and cGMP data, calculated as per $\mu \mathrm{g}$ protein, were compared by analysis of variance followed by Duncan's multiple-range test, where appropriate (Proc GLM; SAS, 1988).

\section{Results}

\section{Dose--response relationships for IBMX}

IBMX elicited a dose-dependent increase in total cAMP $(P<0.001)$ and $c$ GMP $(P<0.01)$ concentrations. Intracellular cAMP and extracellular cGMP concentrations were highest at $10 \mathrm{mmol}$ IBMX $1^{-1}$, whereas extracellular CAMP and 


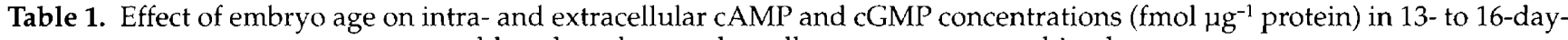
old cattle embryos when all treatments are combined

\begin{tabular}{lccccc}
\hline Embryo age (days) & Number of embryos & Intracellular cAMP & Extracellular cAMP & Intracellular cGMP & Extracellular cGMP \\
\hline 13 & 27 & $52.33 \pm 4.977$ & $39.46 \pm 6.717$ & $0.63 \pm 0.083$ & $3.27 \pm 0.362$ \\
14 & 24 & $56.59 \pm 4.931$ & $36.75 \pm 7.009$ & $0.62 \pm 0.077$ & $2.22 \pm 0.364$ \\
15 & 29 & $39.68 \pm 4.529$ & $43.65 \pm 5.901$ & $0.14 \pm 0.069$ & $0.99 \pm 0.312$ \\
16 & 24 & $28.29 \pm 4.915$ & $21.61 \pm 6.446$ & $0.14 \pm 0.075$ & $0.19 \pm 0.339$ \\
\hline
\end{tabular}

Values are least-square means $\pm \mathrm{SEM}$.

Table 2. Effect of treatment with forskolin, cholera toxin, or forskolin and cholera toxin on intra- and extracellular cAMP and

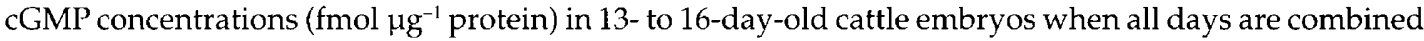

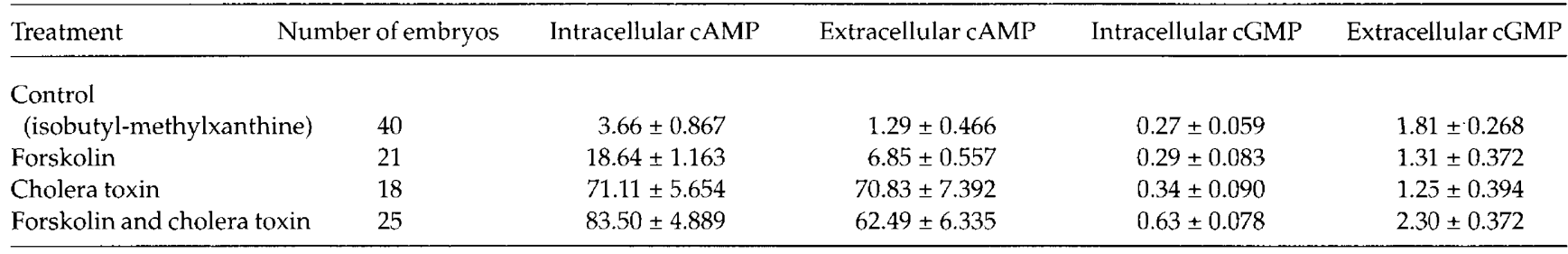

Values are least-square means \pm SEM.

intracellular cGMP concentrations reached a maximum at $1 \mathrm{mmol}$ IBMX $\mathrm{l}^{-1}$ and there was no further increase at $10 \mathrm{mmol} \mathrm{l}^{-1}$. IBMX at $0.1 \mathrm{mmol} \mathrm{l}^{-1}$ did not elicit an increase in the concentration of cAMP or cGMP (Fig. 1a,b).

\section{Dose-response relationships for forskolin}

Forskolin elicited a dose-dependent increase in total cAMP $(P<0.001)$, but had no significant effect on cGMP concentrations. Intracellular cAMP concentrations were highest at $100 \mu \mathrm{mol}$ forskolin $\mathrm{l}^{-1}$, while the increase in extracellular CAMP was smaller and was maximal at $10 \mu \mathrm{mol}$ $\mathrm{1}^{-1}$ and there was no further increase at $100 \mu \mathrm{mol} \mathrm{l}^{-1}$ (Fig. 1c,d).

\section{Dose-response relationships for cholera toxin}

Cholera toxin elicited a large increase in total cAMP concentrations $(P<0.001)$ at all concentrations examined. The intracellular cAMP response was maximal at $0.2 \mu \mathrm{g} \mathrm{ml}^{-1}$ and there was a smaller response at the highest concentration $\left(20 \mathrm{~g} \mathrm{ml}^{-1}\right)$. Extracellular concentrations of cAMP were highest at $2 \mu \mathrm{g}$ cholera toxin $\mathrm{ml}^{-1}$ and also decreased at the highest concentration. Cholera toxin did not affect intracellular CGMP concentrations, but extracellular concentrations increased at $20 \mu \mathrm{g} \mathrm{ml}^{-1}(P<0.05 ; \mathrm{Fig} .1 \mathrm{e}, \mathrm{f})$. On the basis of these results, IBMX $\left(1 \mathrm{mmol} \mathrm{l}^{-1}\right)$ was included in all subsequent treatments, and forskolin and cholera toxin were used at $100 \mu \mathrm{mol} \mathrm{l}^{-1}$ and $2 \mu \mathrm{g} \mathrm{ml}^{-1}$, respectively, to avoid the non-specific effects observed at the higher concentrations.

\section{Overall treatment effects in 13- to 16-day-old embryos}

Overall analysis of variance, in which all treatments were included, was conducted on the data. The effects of embryo age across treatments and of treatments over all days examined are summarized (Tables 1 and 2, respectively). The analysis of variance showed that intra- and extracellular cAMP concentrations were increased by treatment with forskolin, cholera toxin, and forskolin and cholera toxin $(P<0.001$; Table 2). Intracellular cAMP concentrations decreased with embryo age from day 13 to day 16 inclusive $(P<0.001$; Table 1$)$ and there was a day $\times$ treatment interaction $(P<0.05)$. Extracellular cAMP tended to decrease with embryo age, but this decrease was not significant $(P=0.074$; Table 1). Intra- and extracellular cGMP decreased with embryo age $(P<0.001$; Table 1$)$, but only intracellular cGMP was significantly increased by treatment with forskolin and cholera toxin $(P<0.01$; Table 2$)$ and there was no day $\times$ treatment interaction.

\section{Effect of forskolin on 13- to 16-day-old embryos}

Forskolin $\left(100 \mu \mathrm{mol} \mathrm{l}^{-1}\right)$ elicited a significant increase in intra- and extracellular cAMP concentrations compared with IBMX controls on days $13,14,15$ and $16(P<0.001$; Fig. 2$)$. There was also a decrease in intra- and extracellular cAMP concentrations with day $(P<0.001)$ and a day $\times$ treatment interaction $(P<0.001)$; the increase in cAMP concentrations elicited by forskolin was lower at days 15 and 16 than at days 13 and 14. Intra- and extracellular cGMP concentrations decreased with day $(P<0.001)$, but there was no effect of forskolin treatment on cGMP concentrations.

In the IBMX controls, there was no significant change in extracellular cAMP with day, but intracellular cAMP and CGMP $(P<0.01)$ and extracellular cGMP $(P<0.001)$ decreased with day.

\section{Effect of cholera toxin on 13- to 16-day-old embryos}

Cholera toxin $\left(2 \mu \mathrm{g} \mathrm{ml}^{-1}\right)$ elicited a significant increase $(P<0.001)$ in intra- and extracellular cAMP concentrations 

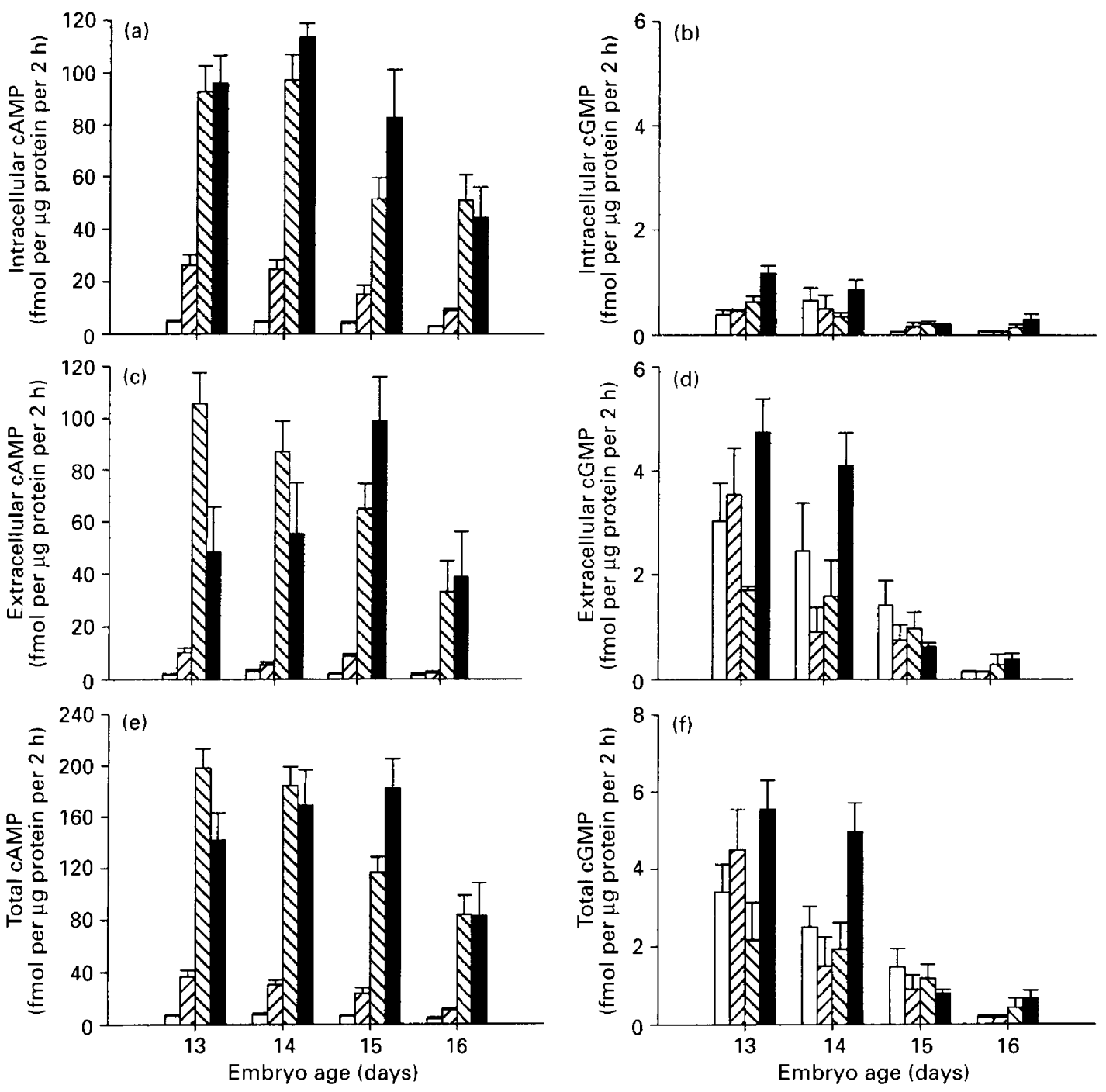

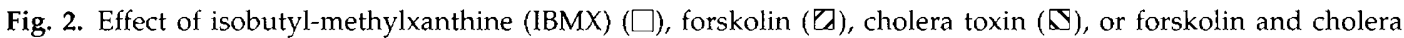
toxin ( $\square$ ) on intracellular, extracellular and total cAMP $(\mathrm{a}, \mathrm{c}, \mathrm{e})$ and cGMP $(\mathrm{b}, \mathrm{d}, \mathrm{f})$ in 13- to 16-day-old cattle embryos. Data represent least-square means \pm SEM of at least four replicates.

compared with IBMX controls on days 13,14, 15 and 16 (Fig. 2). Intra- and extracellular cAMP concentrations decreased with day $(P<0.01)$ and there was a day $x$ treatment interaction $(P<0.01)$. Intra- and extracellular cGMP concentrations decreased with day $(P<0.01)$ but there was no effect of cholera toxin on cGMP concentrations. Cholera toxin $\left(2 \mu \mathrm{g} \mathrm{ml}^{-1}\right)$ elicited higher intra- and extracellular CAMP concentrations than forskolin $(P<0.001)$.

\section{Effect of combined treatment with forskolin and cholera toxin in 13- to 16-day-old embryos}

Combined treatment with forskolin $\left(100 \mu \mathrm{mol} \mathrm{l}^{-1}\right)$ and cholera toxin $\left(2 \mu \mathrm{g} \mathrm{ml}^{-1}\right)$ elicited a significant increase in intra- and extracellular cAMP concentrations compared with IBMX controls on days 13, 14,15 and 16 ( $P<0.001$; Fig. 2$)$. Intracellular cAMP concentrations also decreased with day $(P<0.05)$ from day 13 to day 16 and there was a day $\times$ treatment interaction $(P<0.05)$. Intra- and extracellular cGMP concentrations decreased with day $(P<0.001)$. Intracellular cGMP concentrations were increased $(P<0.005)$, whereas extracellular cGMP concentrations were unaffected by combined treatment with forskolin and cholera toxin.

Forskolin and cholera toxin in combination elicited higher concentrations of intra- and extracellular cAMP $(P<0.001)$ and cGMP $(P<0.05)$ than forskolin alone. There was no significant difference between total intra- and extracellular cAMP concentrations elicited by forskolin and cholera toxin together and cholera toxin alone. However, forskolin and cholera toxin in combination elicited higher concentrations of intracellular cGMP than cholera toxin alone.

The overall effect of the treatments was demonstrated by examining total cAMP or cGMP concentrations (Fig. 2e,f). Total cAMP concentrations in the IBMX controls showed a small decrease from day 13 to day 16 (1.6-fold; $P<0.05)$. 
Total cAMP concentrations were increased by forskolin $(P<0.001)$ and decreased steadily with day from day 13 to day 16 (3.3-fold; $P<0.001)$. The increase in total cAMP concentrations elicited by cholera toxin $(P<0.001)$ was much larger than that elicited by forskolin, and also decreased between day 13 and day 16 ( 2.4 -fold; $P<0.05)$. After combined treatment with forskolin and cholera toxin the increase in total cAMP concentrations was similar to that elicited by cholera toxin alone. Concentrations were 1.7-fold lower in 16-day-old embryos than in 13-day-old embryos $(P<0.05)$.

Total cGMP concentrations were not affected by any of the treatments. There was a marked decrease in cGMP concentrations between day 13 and day 16, which was observed across all treatments and ranged from a fivefold decrease after treatment with cholera toxin $(P<0.05)$ to a 23 fold decrease after forskolin $(P<0.001)$.

\section{Discussion}

The results of the present study indicate that adenylyl cyclase is present in 13- to 16-day-old cattle embryos and is capable of activation, directly and indirectly. There is a significant effect of embryo age on cGMP and CAMP, and both basal and activated concentrations decrease significantly from day 13 to day 16.

On the basis of the results of the dose-response study, 1 mmol IBMX $1^{-1}$ was used in the subsequent experiments. The increase in CAMP and cGMP accumulation in cattle embryos after IBMX treatment is most likely the result of a decrease in the breakdown of cAMP and cGMP due to the effect of IBMX on phosphodiesterase activity, rather than to increased formation of these cyclic nucleotides. Although

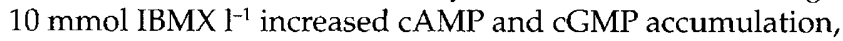
this amount was not used, since at such concentrations IBMX acts as an adenosine receptor antagonist (Fredholm et al., 1994). A concentration of $1 \mathrm{mmol}$ IBMX $\mathrm{l}^{-1}$ effectively prevented cyclic nucleotide hydrolysis.

In the dose-response study, $100 \mu \mathrm{mol}$ forskolin $\mathrm{l}^{-1}$ was the most effective concentration and this was used in subsequent experiments. This concentration of forskolin was effective in activating adenylyl cyclase in mouse and cattle oocytes (Schultz et al., 1983; Bilodeau et al., 1993). In the present study, the increase in total cAMP concentrations in cattle embryos elicited by forskolin ranged from 5.5-fold at day 13 to 2.7-fold at day 16. This is lower than the 25-fold increase in zona-free cattle oocytes reported by Bilodeau et al. (1993) who used the same concentration of forskolin, but it is within the range reported by Manejwala et al. (1986) who used $100 \mu \mathrm{mol} \mathrm{1}^{-1}$ for mouse oocytes and $25 \mu \mathrm{mol} \mathrm{1}^{-3}$ for preimplantation mouse embryos. Therefore, it appears that the adenylyl cyclase in 13- to 16-day-old cattle embryos is less responsive to forskolin than that present in cattle oocytes.

The large increase in cAMP concentrations induced by cholera toxin in cattle embryos is in contrast to mouse and cattle oocytes in which cholera toxin is a much less effective activator than forskolin (Manejwala et al., 1986; Bilodeau et al., 1993), but is consistent with mouse blastocysts in which cholera toxin is more effective than forskolin. However, in mouse blastocysts, cholera toxin induces only a 12-fold increase in CAMP over IBMX controls compared with an increase of 20- to 25-fold in the present study.

The increase in cGMP concentrations elicited by cholera toxin at $20 \mu \mathrm{g} \mathrm{ml}^{-1}$ was unexpected, since cholera toxin is a specific activator of adenylyl cyclase. Although there are no similar reports for embryos, Ledoux et al. (1997) reported increased cGMP concentrations in renal cells after treatment with cholera toxin $\left(20 \mu \mathrm{g} \mathrm{ml}^{-1}\right)$. They proposed that the effect was due to modulation of cGMP production by PKA through an intermediary protein.

The increase in intra- and extracellular cAMP concentrations induced by combined treatment with forskolin and cholera toxin was similar to that elicited by cholera toxin alone, but greater than that elicited by forskolin alone. This lack of synergism of forskolin and cholera toxin is in contrast to the study of Manejwala et al. (1986) in mouse blastocysts in which a fivefold increase in cAMP concentrations was observed after combined treatment with forskolin and cholera toxin compared with cholera toxin alone. However, forskolin is relatively more potent and cholera toxin relatively less potent in mouse blastocysts compared with the cattle blastocysts used in the present study in which maximum stimulation of adenylyl cyclase was achieved with $2 \mu \mathrm{g}$ cholera toxin $\mathrm{ml}^{-1}$ and the addition of forskolin was unable to increase the response further. However, a small increase in intracellular cGMP concentrations compared with IBMX controls was observed after combined treatment with forskolin and cholera toxin, and this was not observed when either activator was administered separately. This increase may be attributed to a modulation of CGMP concentrations by PKA similar to that proposed by Ledoux et al. (1997) for renal cells after treatment with $20 \mu \mathrm{g}$ cholera toxin $\mathrm{ml}^{-1}$.

A consistent finding in the results of the present study was the large decrease in CGMP concentrations in 16-day-old compared with 13- and 14-day-old embryos. An equally consistent but smaller decrease was observed for cAMP. Grealy et al. (1996) reported a marked increase in embryo size and protein content during this time. Since cGMP inhibits proliferation in vascular smooth muscle cells (Sarkar et al., 1997; Yu et al., 1997) and osteoblastic cells (Hagiwara et al., 1996), it is possible that the decrease in cGMP concentrations in 15- to 16-day-old embryos is a signal for proliferation within the embryo. Nitric oxide, which acts by increasing cGMP concentrations, is produced by preimplantation mouse embryos and is required for their development (Gouge et al., 1998). However, high concentrations of nitric oxide inhibit both embryo development in vitro and implantation in vivo in mice (Barroso et al., 1998). Therefore, it is possible that the decrease in CGMP concentrations during the days leading up to implantation in cattle embryos reflects a decrease in nitric oxide production by the embryo. In addition, whereas intracellular cAMP concentrations are consistently higher than extracellular concentrations across all treatments, the opposite is the case for cGMP. This indicates that cGMP has an important role as an extracellular messenger in addition to its intracellular role.

The present study augments the data on the export of cAMP and cGMP by cattle embryos (Grealy et al., 1997). In 
the present study, changes in intracellular cAMP and cGMP concentrations were reflected by changes in their extracellular concentrations. The roles of extracellular cAMP and CGMP have not been elucidated. One possibility is that they are degraded by a series of extracellular enzymes to adenosine and guanosine, which may, in turn, act as a signal via purinergic receptors either within the embryo or between the embryonic and maternal tissues. Purinergic receptors have been identified in bovine oviduct epithelial cells (Cox and Leese, 1995) and in mouse (Chan et al., 1997), rat (Dehpour et al., 1994) and guinea-pig (Haynes and Pennefather, 1993; Piper and Hollingsworth, 1996) uterine epithelia, although there are no reports of their presence in embryos. Adenosine, acting via increased cAMP concentrations, inhibits proliferation in smooth muscle cells (Jonzon et al., 1985). Decreased cAMP concentrations may therefore stimulate proliferation.

This work was supported by the EC Biotech $3^{\text {rd }}$ Framework Programme (Contract CT-92-0163). The authors thank J. P. Hanrahan and M. G. Diskin for statistical advice, H. J. Leese for constructive criticism of the manuscript, A. Glynn, P. Joyce, G. Morris, W. Connolly and J. Nally for technical support, and G. Burke and P. Creaven for care of the animals.

\section{References}

Amlal H, Legoff C, Vernimmen C, Paillard M and Bichara M (1996) $\mathrm{Na}^{+}-\mathrm{K}^{+}\left(\mathrm{NH}_{4}^{+}\right)-2 \mathrm{Cl}^{-}$cotransport in medullary thick ascending limb: control by PKA, PKC, and 20-HETE American journal of Physiology 271 C455-C463

Barber R and Butcher RW (1983) The egress of cyclic AMP from metazoan cells. In Advances in Cyclic Nucleotide Research pp 119-138 Eds P Greengard and GA Robison. Raven Press, New York

Barroso RP, Osuamkpe C, Nagamani M and Yallampalli C (1998) Nitric oxide inhibits development of embryos and implantation in mice Molecular Human Reproduction 4 503-507

Betteridge KJ, Eaglesome MD, Randall GCB and Mitchell D (1980) Collection, description and transfer of embryos from cattle 10-16 days after oestrus Journal of Reproduction and Fertility 59 205-216

Bilodeau S, Fortier MA and Sirard MA (1993) Effect of adenylate cyclase stimulation on meiotic resumption and cyclic AMP content of zona-free and cumulus-enclosed bovine oocytes in vitro. Journal of Reproduction and Fertility $975-11$

Boynton AL and Whitfield JF (1983) The role of cyclic AMP in cell proliferation: a critical assessment of the evidence. In Advances in Cyclic Nucleotide Research pp 193-294 Eds P Greengard and GA Robison. Raven Press, New York

Chan HC, Liu CQ, Fong SK, Law SH, Wu LJ, So E, Chung YW, Ko WH and Wong PY (1997) Regulation of $\mathrm{Cl}^{-}$secretion by extracellular ATP in cultured mouse endometrial epithelium Journal of Membrane Biology 156 45-52

Christensen ST, Kemp D, Quie H and Rasmussen L (1996) Cell death, survival and proliferation in Tetrahymena thermophila. Effects of insulin, sodium nitroprusside, 8-bromo cyclic GMP, NG-methyl-L-arginine and methylene blue Cell Biology International 20 653-666

Cox CJ and Lesse HJ (1995) Effect of purinergic stimulation on intracellular calcium concentration and transepithelial potential difference in cultured bovine oviduct cells Biology of Reproduction 52 1244-1249

Dehpour AR, Jabbary M, Shadan F and Ghafourifar P (1994) Possible evidence for involvement of new subtype of $P_{1}$-purinoceptors in rat isolated uterus General Pharmacology 25 515-519

Dumont JE, Jauniaux J-C and Roger PP (1989) The cyclic AMP-mediated stimulation of cell proliferation Trends in Biochemical Sciences 14 67-71

Fishman PH (1990) Mechanism of action of cholera toxin. In ADP-Ribosylating Toxins and G Proteins. Insights into Signal Transduction pp 127-140 Eds J Moss and $M$ Vaughan. American Society for Microbiology, Washington DC

Fredholm BB, Abbracchio MP, Burnstock G, Daly JW, Harden TK, Jacobson KA, Leff P and Williams M (1994) Nomenclature and classification of purinoceptors Pharmacological Reviews 46 143-156

Garcia-Ocana A, Penaranda C and Esbrit P (1996) Comparison of antiproliferative effects of atrial natriuretic peptide and transforming growth factor beta on rabbit kidney proximal tubule cells Life Sciences $\mathbf{5 8}$ 251-258

Gouge RC, Marshburn P, Gordon BE, Nunley W and Huet-Hudson YM (1998) Nitric oxide as a regulator of embryonic development Biology of Reproduction 58 875-879

Goy MF (1991) CGMP: the wayward child of the cyclic nucleotide family Trends in Neuroscience 14 293-298

Grealy M, Diskin MG and Sreenan JM (1996) Protein content of cattle oocytes and embryos from the two-cell to elongated blastocyst stage at day 16 Journal of Reproduction and Fertility 107 229-233

Grealy M, Glynn MA and Sreenan JM (1997) Cyclic AMP and cyclic GMP concentrations in, and efflux from, preimplantation cattle embryos Animal Reproduction Science 48 175-185

Hagiwara H, Inoue A, Yamaguchi A, Yokose S, Furuya M, Tanaka S and Hirose $S$ (1996) cGMP produced in response to ANP and CNP regulates proliferation and differentiation of osteoblastic cells American Journal of Physiology Cell Physiology 39 C1311-C1318

Hamet P and Tremblay J (1991) Evaluating atrial natriuretic peptide-induced cGMP production by particulate guanylyl cyclase stimulation in vitro and in vivo. In Adenylyl Cyclase, G Proteins and Guanylyl Cyclase pp 447-461 Eds RA Johnson and JD Corbin. Academic Press, San Diego, CA

Haynes JM and Pennefather JN (1993) $A_{1}$ and $A_{2}$-purinoceptors in the guineapig uterus Clinical and Experimental Pharmacology and Physiology 20 609-617

Jonzon B, Nilsson J and Fredholm BB (1985) Adenosine receptor-mediated changes in cyclic AMP production and DNA synthesis in cultured arterial smooth muscle cells Journal of Cellular Physiology 124 451-456

Ledoux S, Dussaule JC, Chatziantoniou C, Ardaillou N, Vandermeersch S and Ardaillou R (1997) Protein kinase A activity modulates natriuretic peptide-dependent CGMP accumulation in renal cells American Journal of Physiology Cell Physiology 41 C82-C89

Manejwala F, Kaji E and Schultz RM (1986) Development of activatable adenylate cyclase in the preimplantation mouse embryo and a role for cyclic AMP in blastocoel formation Cell 46 95-103

Piper AS and Hollingsworth $\mathbf{M}$ (1996) $P_{2}$-purinoceptors mediating spasm of the isolated uterus of the non-pregnant guinea-pig British Journal of Pharmacology 117 1721-1729

Sarkar R, Gordon D, Stanley JC and Webb RC (1997) Dual cell cycle-specific mechanisms mediate the antimitogenic effects of nitric oxide in vascular smooth muscle cells Journal of Hypertension 15 275-283

SAS (1988) SAS User's Guide: Statistics SAS Institute Inc., Cary, NC

Schultz RM, Montogomery RR and Belanoff JR (1983) Regulation of mouse oocyte meiotic maturation: implication of a decrease in oocyte cAMP and protein dephosphorylation in commitment to resume meiosis Developmental Biology 97 264-273

Seamon KB and Daly JW (1981) Forskolin: a unique diterpene activator of cyclic AMP-generating systems Journal of Cyclic Nucleotide Research 7 201-224

Sunahara RK, Dessauer CW and Gilman AG (1996) Complexity and diversity of mammalian adenylyl cyclases Annual Review of Pharmacology and Toxicology $36461-480$

Yu SM, Hung LM and Lin CC (1997) cGMP-elevating agents suppress proliferation of vascular smooth muscle cells by inhibiting the activation of epidermal growth factor signalling pathway Circulation 95 1269-1277 